DOI: 10.17805/ggz.2018.6.2

\title{
«Трагическая история доктора Фауста»: вопросы датировки и издания ${ }^{*}$
}

\author{
B. С. Макаров
}

Православный Свято-Тихоновский гуманитарный университет, 2. Москва

Отказ от «мифобиографического» подхода к творчеству Кристофера Марло - важный шаг на пути к тому, чтобы более точно определить его роль в английской литературе и культуре кониа XVI - начала XVII века. Применительно к «Трагической истории доктора Фауста» этот шаг затрудняет сама исключительная роль Фауста как культурного европейского героя. Обзор существующих и выдвижение дополнительных гипотез о возможной датировке, первых постановках и изданиях трагедии - три задачи, которая ставит перед собой настоящая статья - поможет на нескольких уровнях связать текст и эпоху, в которую он был создан. На основании этих новых гипотез новое академическое издание «Фауста» в серии «Литературные памятники» предложило более сложную жанровую и философскую интерпретачию трагедии Марло.

Ключевые слова: «Трагическая история доктора Фауста»; К. Марло; лондонские театры; книгоиздание в Англии; Филип Хенсло; Эдвард Эллин; Дюжон Райт

\section{“The Tragical History of Doctor Faustus": Dating and Publication}

\author{
V. S. Makarov
}

St. Tikhon's Orthodox University, Moscow

Overcoming the "mythobiographical" fallacy in studying the works of Christopher Marlowe is an important step towards reviewing the role he played in late 16th - early 17th century English culture. In the case of "The Tragical Histo-

\footnotetext{
* Статья подготовлена в рамках проекта «Кристофер Марло и его творчество в русской и мировой культуре: междисциплинарный взгляд» при финансовой поддержке Российского фонда фундаментальных исследований (грант № 18 -012-00679).

The article was prepared within the framework of the project "Christopher Marlowe and His Literary Heritage in Russian and World Culture: An Interdisciplinary Look" with financial support from the Russian Foundation for Basic Research (grant No. 18-012-00679).
} 
ry of Dr. Faustus", the task is even more complicated, as Faustus has come to be perceived as a unique European cultural hero. This article aims to review, clarify and complement the existing hypotheses on the possible dating of "The Tragical History", as well as its earliest stagings and editions, which can help further link the text to the time of its composition on multiple levels. It was on some of these hypotheses that a new Russian academic edition of "The Tragical History" was based in order to suggest a more complex genre and philosophic interpretation of Marlowe's famous tragedy.

Keywords: "The Tragical History of Doctor Faustus"; C. Marlowe; London theatres; book publishing in England; Philip Henslowe; Edward Alleyn; John Wright

\section{ВВЕДЕНИЕ}

Из всего небольшого корпуса пьес Кристофера Марло (1564-1593) «Трагическая история доктора Фауста», вероятно, имеет самую непростую судьбу. Две версии текста, известные под условными обозначениями «А» и «Б», отличаются друг от друга более чем на треть, причем не только наличием или отсутствием отдельных сцен, но и тем, написан ли тот или иной фрагмент в стихах или в прозе. Разногласия в вопросе об аутентичности версий длятся уже более полутора столетий и в значительной степени подпитывают дискуссию об отражении драматической биографии самого Марло в его творчестве.

Романтизация - вслед за жизнью - творчества Марло создала за последние сто лет его «мифобиографический» культ, если использовать термин, которым Н. В. Захаров описывает примеры изображения Марло в современной массовой культуре (Захаров, 2018). Демонстративно презирающий меру и границу во всем “overreacher", каким Гарри Левин описывал героя марловских трагедий (Levin, 1952), часто видится и в самом Марло, чему способствует неоднозначная репутация драматурга, щедро подкрепленная доносами и показаниями под давлением.

Мифобиография, разумеется, имеет право на существование. Многие десятилетия она предлагала простую и понятную интерпретацию марловского канона как поиска и постоянного конструирования трансгрессии - в интеллектуальном поиске (Фауст), в политической практике (Тамерлан и Гиз) и т. д., предполагая сложный кульбит в построении конфликта: интересуясь запретным и стремясь к нему, автор все время выводит своих героев за пределы морального и завершает конфликт их неизбежным наказанием. 
Для того чтобы прояснить, насколько реальность сложнее и многоплановее этой схемы, необходима междисциплинарная - при всей неоднозначности и заезженности этого термина — работа на нескольких уровнях. Вопервых, и этому служит настоящая статья, российский читатель должен привыкнуть к сложности поэтики Марло и ее принципиальной несводимости к тиражированию однотипного конфликта. Для этого необходимо кардинально расширить взгляд на пьесу, включая ее сложные места и контексты создания. Во-вторых, необходимо максимально проследить философские, богословские и т. д. аллюзии, создающие в тексте «эффект сложности». В последние годы в России такую задачу постаралось выполнить издание «Трагической истории доктора Фауста» в серии «Литературные памятники», среди подготовителей которого был и автор данной статьи (Марло, 2019).

Фауст, как и Гамлет, разумеется, давно стал «вечным героем» мировой литературы, и, когда речь заходит о преодолении мифобиографизма, контекстуализация помогает избавиться от излишнего пиетета. Применительно к Фаусту, важно и остранение привычного для нас по «гетевской» инерции сочувствия к главному герою, хотя и очевидно, что катартическое сострадание во многом создает сама драматическая ситуация, где Фаусту необходимы длинные монологи. Долгая культурная история Фауста как драматического героя еще усложняет его сценическую и читательскую судьбу, но загадочной она была с самого начала в Лондоне 1580-1590-х гг. Как показано в статье А. Н. Горбунова, она вполне может быть описана метафорой маятника: от приоритета текста А к тексту Б и обратно (Горбунов, 2019: 178). Выходом из режима «маятника» может служить схема, где оба текста публикуются параллельно, со всеми своими особенностями. Ее пионером стал сэр Уолтер Уилсон Грег еще в середине XX века (Marlowe's Doctor Faustus ... , 1950), такая схема принята и для российского издания 2019 г. Увы, ее невозможно применить на сцене - постановщику придется либо выбрать один из вариантов, либо соединить их фрагменты. Парадоксально, но в современной ситуации это отсутствие единства может пойти на пользу режиссеру, заставляя его размышлять о том, что хотя «начала» и «концы» сюжетов в значительной степени совпадают, путь к ним, в сущности, состоит из калейдоскопического набора сцен, которые можно перемонтировать по-разному.

ДАТИРОВКА:

ТЕКСТУАЛЬНЫЕ И ИСТОРИЧЕСКИЕ АРГУМЕНТЫ

За полтораста лет накопилось немало аргументов в пользу одной из двух датировок «Фауста» - ранней или поздней. Пьеса могла быть написана 
фактически сразу после поражения испанской Великой армады - в 15881589 гг., либо в 1592 или даже 1593 г., в последние годы жизни Марло. Разберем основные аргументы в пользу каждой из версий, которые можно разделить на несколько групп - аргументы «текстуальные», связанные с выходом источников, из которых Марло почерпнул сюжетные детали; «исторические», связанные с упоминанием реальных событий; и «театральные» - детали известных нам ранних постановок.

Общепринятый terminus post quem - 1587 год, когда во франкфуртской типографии Иоганна Шписа была отпечатана т. н. «народная книга» (volksbuch, т. е. предназначенная для массового чтения, эквивалент английского термина “chapbook”) “Historia von D. Johann Fausten”. Теоретически Марло мог быть знаком и с более ранним рукописным текстом, но вероятно, это слишком смелое предположение, и стоит остановиться на том, что книга могла оказаться в Англии уже через несколько недель после выхода. Неизвестно, знал ли Марло немецкий, а английский ее перевод, вышедший под инициалами переводчика — Р. F. — появился лишь в 1592 г. (The historie ... , 1592). Однако ряд комментаторов не без оснований утверждают, что, уже судя по фразе «с исправлениями по франкфуртской копии» (“in convenient places imperfect matter amended: according to the true copie printed at Franckfort"), скоpeе всего, это не первое издание перевода, и что английская легенда о Фаусте могла выйти в свет даже раньше, чем немецкая - при условии, что одна из рукописей попала в руки некоему англичанину, который успел снять с нее копию. Таинственный П. Ф. в таком случае мог быть даже не первым переводчиком, а тем, кто исправил перевод и привел его в соответствие с франкфуртским изданием.

У. У. Грег был первым, кто исследовал историю издания перевода П. Ф., который не был занесен, как требовалось, в Реестр компании книготорговцев, но в декабре 1592 г. стал предметом внутреннего разбирательства в гильдейском суде, где издатель Абель Джефс успешно защитил свое право на рукопись, несмотря на то, что его оспаривал Томас Орвин (Marlowe’s Doctor Faustus ... , 1950: 3-4). Детали этого запутанного дела до конца не ясны. Очевидно, что рукопись, оказавшаяся у Орвина, была неполной (более ранний вариант или с пропусками?), но когда он сам ее издал, неясно (Грег полагает, что тоже в 1592 г., но раньше, весной - хотя не исключена и еще более ранняя дата). К сожалению, по-прежнему загадкой остается личность П. Ф. Ряд комментаторов полагает, что он был связан с Кембриджским университетом, а таинственная немецкая рукопись (если она существовала в Англии) хранилась там, и Марло мог с ней познакомиться едва ли не студентом. 
К сожалению, ненадежными доказательствами остаются и текстуальные параллели: учитывая необходимость отказаться от современной репутации как доказательного аргумента, многочисленные параллели между «Фаустом» и современными ему пьесами не могут показать, кто у кого заимствовал.

Два основных примера таких параллелей — это значительные сюжетные совпадения между «Фаустом» Марло и «Монахом Бэконом и монахом Банги» Роберта Грина, который косвенно датируется примерно 1589 г. (Marlowe’s Doctor Faustus ... , 1950: 7). Однако и здесь замешивается репутационная логика: гораздо легче себе представить, что у Марло заимствовал «беспутный» Грин, чем наоборот. Это же касается анонимной комедии «Укрощение одной строптивицы» (The Taming of a Shrew), написанной в 1588-1589 гг. и в дальнейшем знаменитой как источник почти одноименной шекспировской комедии (ibid: 8). Кроме повторенной близко к тексту шутки об обледенелой бороде Борея, в ней есть и другие параллели, но, как верно указывает Грег, мы вынуждены опираться на издания, появившиеся как минимум 5-6, а то и 10 лет спустя. За прошедшие годы текст мог быть изменен.

Наконец, Грег считает сильным аргументом в пользу ранней датировки рукописные маргиналии на полях книги Джона Леланда, сделанные, вероятнее всего, Томасом Нэшем (ibid). Одна из них очевидно расшифровывается как "che sara sara deuinynitie adieu", т. е. явная цитата из сцены 1 «Фауста». Книга вышла в 1589 г., и Грег, вслед за обнаружившим этот экземпляр и маргиналии в нем Полом Кочером, полагает, что они могли быть сделаны сразу после выхода книги в свет.

Оставаясь приверженцем более поздней датировки, Грег в качестве самого сильного аргумента вновь использует репутационный: ему трудно поверить, что выказывающий «зрелую духовность» «Фауст» написан практически сразу после «юношески грубого» «Тамерлана» (ibid: 9-10). Аргумент серьезный, но только если полагать, что путь драматурга - это постоянный взлет. Эту логику позже повернул в обратную сторону Курт Зимански, показав, что если как персонаж Фауст и сложнее Тамерлана, то композиция самой пьесы в любом из имеющихся вариантов оставляет желать лучшего (Zimansky, 1962: 181).

В 1940-1950-е гг. раннюю датировку защищал ряд исследователей, прежде всего П. Кочер. Кроме возможных маргиналий Нэша, он обнаружил возможную параллель с «Фаустом» в написанном в форме диалога трактате против ведьм Генри Холланда (Treatise against Witchcraft). Изданный в 1590 г. в Кембридже трактат утверждает, что ведьмы и колдуны никуда летать не мо- 
гут, а обманчивое ощущение полета им насылает дьявол. На полях против этого фрагмента указаны два имени - «Фауст» (Faustus) и «пьяный Дунстан» (Drunken Dunstan) (Kocher, 1940: 96). Слово "Faustus" написано в латинизированной форме, именно так, как оно появляется в переводе П. Ф. и у Марло - а не в немецкой, как в «народной книге», из чего Кочер делает вывод, что как минимум перевод в то время уже существовал. Еще одна известная Кочеру маргиналия, оставленная Гэбриэлем Харви на полях «Стратегематикона» Секста Юлия Фронтина, в которой упоминается способность Фауста возводить замки и посылать в бой вооруженных дьяволов (ibid: 99-100), приводит его к выводу, что круг интересующихся легендой о Фаусте как-то связан с Кембриджем, где учились Марло, Харви, Нэш и, возможно, П. Ф. Кембриджские корни популярности легенды о Фаусте рассматривает и Джеральд М. Пинкисс, но уже в связи с полемикой Марло с кальвинистами, прежде всего с Уильямом Перкинсом (Pinciss, 1993).

В несколько более поздней статье Кочер видит параллель с «Фаустом» в рассуждении Харви о некроманте, подобно Фаусту, вызывающем духов - с которым он сравнивает своего анонимного памфлетного оппонента "double V” (т. е. Нэша - Kocher, 1943: 539-540). В этой же статье Кочер обращается и к утраченной балладе о Фаусте, известной из записи в Реестре компании книготорговцев от 28 февраля 1589 г. под названием “A Ballad of the Life and Deathe of Doctor Ffaustus the Great Cunngerer" [Conjuror]. Кочер предполагает, что такое близкое совпадение не случайно, и ранние «фаустовские» тексты перевод народной книги и «баллада» - появились на гребне моды в 15881589 гг, а соответственно, и Марло не обязательно было ждать до 1592 г.

Права на балладу, согласно записи в Реестре, были закреплены за известным издателем популярной литературы (прежде всего баллад и памфлетов) Ричардом Джонсом (ум. не ранее 1613). На издание было получено разрешение епископа Лондонского (Джона Эйлмера, 1521-1594). В 1590 г. Джонс издаст «Тамерлана» Марло (обе части под одной обложкой), а в 1592 г. — первое издание «Пирса Безгрошового» Т. Нэша.

Ряд исследователей полагает, что текст баллады о Фаусте, возможно, с некоторыми изменениями, дошел до нас в варианте конца XVII века (The judgment of God ..., 1695: Электронный ресурс). Действительно, в балладе упоминаются и чудеса Фауста, и полет его сквозь небеса, и отречение от богословия. Она выступает как своеобразное краткое содержание «народной книги» в переводе П. Ф. и во многом сюжетно совпадает с «Фаустом» Марло.

«Исторические» аргументы датировки Фауста связаны с отсылками к событиям войны за независимость Нидерландов и в целом тоже поддержива- 
ют раннюю версию (1588-1589). Так, в мечтах Фауст хочет изгнать из страны «князя Пармского» - Александра Фарнезе, герцога Пармы, Пьяченцы и Кастро (1545-1592), племянника испанского короля Филиппа II, с 1578 г. до смерти - наместник Испанских Нидерландов. Для англичан было несколько причин ждать «изгнания» герцога Пармского: войска под его командованием несколько раз наносили поражение английскому экспедиционному корпусу в Нидерландах. В 1588 г. Великая армада под командованием герцога МединаСидонии должна была взять на борт 30000 солдат под командованием Фарнезе и высадиться в Англии. В последние годы наместничества (с 1590) герцог был занят участием во французских религиозных войнах на стороне Католической лиги, где и был тяжело ранен при осаде г. Кодебек. Последние полгода жизни был прикован к постели, что делает упоминание его более актуальным в 1588-1589 гг., чем в 1592 г.

Вторая отсылка напоминает о событиях июля 1584 - августа 1585 г., когда армия герцога Пармского осаждала крупнейший порт мятежных провинций - Антверпен, лежащий в устье реки Шельды. Чтобы помешать осажденным получить помощь с моря, по приказу Фарнезе в феврале 1585 г. через Шельду был построен 800-метровый понтонный мост, а у обоих его концов - хорошо укрепленные форты. В ответ осажденные превратили более 30 кораблей в брандеры, а два т. н. «адских поджигателя» (hellebranders) - в колоссальные пороховые погреба, содержавшие, по некоторым сообщениям, более трех тонн пороха каждый. На «поджигателях» были установлены специальные заряды замедленного действия и пороховые камеры, которые должны были равномерно направить силу взрыва вперед и в стороны. В ночь на 5 апреля 1585 г. под огненной завесой обычных брандеров корабли были направлены вниз по Шельде. Один из них уткнулся в берег, и заряд не сдетонировал, зато взрыв второго - «Надежды» (“De Ноop”) проделал в мосту шестидесятиметровую брешь и уничтожил несколько сот испанских солдат. Вспоминая об огненном корабле, Фауст мечтает, что ему будут служить еще более странные орудия ("stranger engines for the brunt of warre”).

И обе отсылки, и сама идея освобождения от испанцев «немецких» (т. е. протестантских) земель, конечно, более актуальны в конце 1580-х гг., сразу после победы над Непобедимой армадой, чем в начале 1590-х гг., когда военная поддержка Нидерландов сократилась, а часть английских экспедиционных войск была выведена.

Но все же и исторические аргументы не могут решить вопрос в пользу одной из датировок. Вероятно, стоит согласиться с марловедом Сарой Мансон Дитс - окончательное решение вряд ли будет возможно, но аргументы в 
пользу более ранней версии все же звучат чуть сильнее (Doctor Faustus ... , 2010: 21-22).

\section{ТЕАТРАЛЬНЫЙ АРГУМЕНТ ДАТИРОВКИ: РАННИЕ ПОСТАНОВКИ «ФАУСТА»}

Право на постановку пьесы (как и почти всех других драм Марло) в первые десятилетия после ее создания, скорее всего, принадлежало единственной театральной компании, от которой сохранилась хоть какая-то документация - «Слугам лорда-адмирала» (Lord Admiral's Men). К сожалению, «Дневник» (а точнее, приходно-расходная книга) антрепренера Слуг лордаадмирала Филипа Хенсло (Philip Henslowe, ок. 1550-1616) начинается только с 1591 г., поэтому более ранняя судьба трагедии о Фаусте, если она была написана в 1588-1589 гг., нам неизвестна.

Вероятнее всего, «Фауст» был поставлена на сцене «Розы» - театра в южном пригороде Лондона Саутворке, принадлежавшего Хенсло с 1587 г. Существует и другая версия, опирающаяся в том числе на упоминание в памфлете Томаса Деккера «Черная книга» (The Blacke Booke, 1604), что от наводнивших театр настоящих дьяволов трещал старый «Театр» - т. е. театральное здание на север от Лондона, которым в конце 1580-х и до 1594 г. владела та же компания. Наконец, в 1630-е гг. юрист Уильям Принн в трактате против театров указывает, что «Фауст» шел на сцене трактира «Белл Сэвидж» (см. подробнее: Колесник, Макаров, 2018)). Возможно, что «Фауст» шел на всех трех сценах - сначала в более фешенебельных «Театре» и «Розе», а когда пьеса потеряла популярность - во дворе трактира, превращенного в театр.

Главную роль, несомненно, играл Эдвард Эллин (Аллейн, Edward Alleyn, 1566-1626), один из наиболее известных елизаветинских трагиков, исполнитель ролей Вараввы в «Мальтийском еврее» и Тамерлана в дилогии Марло, впоследствии основатель Далвич-колледжа, в архиве которого и сохранились документы Хенсло (Эллин был его зятем). Если верна версия о более ранней датировке «Трагической истории...» (1588-1589), то Фауста вначале мог играть и другой актер Слуг лорда-адмирала, либо Эллин, формально связанный в то время с труппой Фердинандо Стэнли, лорда Стрэнга (Lord Strange’s Men), выступал в постановке как приглашенный актер.

В сборнике сатир и эпиграмм Сэмюэла Роулендса «Крестовый валет» (The Knave of Clubs, 1609) упоминается неудачливый щеголь, который, пытаясь вызвать дьявола, одевается в «широкие одежды» (surplis, дословно стихарь) с крестом на груди, «как Эллин в роли Фауста»: 
The Gull gets on a surplis,

With a crosse vpon his breast,

Like Allein playing Faustus

In that manner he was drest.

(Rowlands, 1872: 29)

В этой цитате интересно, что, в отличие от марловского героя, щеголь Роулендса руководствуется не оккультными книгами, авторы которых прямо называются в тексте трагедии, а тем, что он видел на сцене. Неясно, зачем Эллин так одевался для сцены вызова Мефистофеля - возможно, для «подстраховки» на случай, если оккультное колдовство сработает не так. Учитывая, что его герой только что отрекся от богословия и от Евангелия, возможно, это давало комический эффект.

В последние годы жизни лорда Стрэнга (1590-1594) обе компании Слуги лорда-адмирала и Слуги лорда-камергера - были фактически объединены под контролем Хенсло. Вначале конфликт с властями Лондона в 15891590 гг., а потом эпидемия чумы 1592-1593 гг., когда театры были закрыты, а актеры гастролировали по провинции, не позволяют с точностью определить, сколько постановок «Фауста» (если версия ранней датировки верна) могло пройти до 1594. 14 мая 1594, почти через год после гибели Марло, Слуги лорда-адмирала в расширенном составе начали новый сезон, и в следующие три года «Фауста» сыграли 24 раза - это немало, если учесть, что каждый год труппа ставила более 30 пьес, из них половину новых. В 1597 г. Эллин покинул сцену, - возможно, это совпало с временным выходом «Фауста» из репертуара компании.

На страницах «Дневника» Хенсло «Фауст» упоминается не раз. 30 сентября 1594 г. Хенсло фиксирует самый большой сбор за весь сезон 3 фунта 12 шиллингов - за один спектакль (“'R<eceive>d at Docter Fostose”) (Henslowe, 1904: 19). Комментаторы полагают, что в этот день памятная по прошлым годам трагедия, вероятно, была возобновлена (или, что маловероятно, «Фауст» был поставлен впервые). Спектакли 3 и 21 октября тоже принесли значительные сборы - 44 шиллинга (т. е. 2 фунта 4 шиллинга) и 33 шиллинга (т. е. 1 фунт 13 шиллингов) соответственно. Примерно такие же сборы обеспечивал «Тамерлан» Марло и несколько новых комедий. С частотой 2-3 раза в месяц «Фауст» шел до весны 1595 г., причем спектакль принес менее 1 фунта только в самый сложный для театра период между Рождеством и Новым годом. 
В других бумагах Хенсло, например, в реестрах реквизита и костюмов, также есть отсылки к постановкам «Фауста» в 1594-1598 гг. - в частности, упоминаются «джеркин и плащ Фауста» (“faustus Jerkin his clok”) (Henslowe, 1907: 54), «два марципана и город Рим» (“ij. marchepanes, and a cittie of Rome”) (ibid: 116), «три бубна» и колесница с драконом или просто «дракон» (“iii. timbrels, i. dragon for fostes”) (ibid: 118), «одна папская митра» (“ј. poopes miter”) (ibid). Возможно, есть и другие, которые не так просто связать с трагедией Марло. Попытки ученых с помощью бумаг Хенсло определить, были ли в «Трагической истории...» в версии 1594-1597 гг. сцены с рогами рыцаря Бенволио и другие присутствующие в тексте Б эпизоды, пока не увенчались успехом.

22 ноября 1602 г. Хенсло отмечает выплату 4 фунтов Сэмюэлу Роули и Уильяму Бёрду за дополнительные сцены к «Фаусту» (“adicyones in docter Fostes”) (Henslowe, 1904: 172). Это очень большая сумма, например, в сравнении с тем, что 2 декабря того же года за новую пьесу «Игра в теннис» (A Set at Tennis) Энтони Манди было заплачено всего 3 фунта, а 14 декабря Т. Миддлтону за новый пролог и эпилог к «Монаху Бэкону...» давно умершего Р. Грина (т. е. объем работы лишь ненамного меньший, чем у Бёрда и Роули) - 5 шиллингов. Кроме популярности марловской трагедии, это можно объяснить и тем, что в отличие от Миддлтона, Манди, Деккера и других наемных драматургов, Роули и Бёрд были актерами труппы Слуг лорда-адмирала.

C. Роули (Samuel Rowley, ?-1624) упоминается в списке актеровпайщиков еще в 1594 г., а в целом в «Дневнике» - несколько десятков раз, в том числе и в связи с денежными делами компании: он нередко покупал костюмы, реквизит и вел переговоры с драматургами о пьесах на заказ. У. Бёрд (или Борн, William Bird (Borne), ?-1624), в бумагах Хенсло упоминается с августа 1597 г. (покупка ткани на «женское платье для Борна» показывает, что он был еще подростком и играл женские роли), вначале как наемный актер в «Розе» с контрактом на 3 года. Его предыдущая компания Слуг графа Пембрука (Earl of Pembroke’s Men) распалась после запрета скандальной пьесы Бена Джонсона и Томаса Нэша «Собачий остров».

В 1598-1599 гг. Бёрд, судя по сохранившимся распискам, нередко брал в долг у Хенсло, а в 1600 г. Хенсло ссудил 3 фунта его жене для выплаты залога за мужа, избившего посыльного, который принес жене некое письмо. До добавлений в «Трагическую историю...» Берд и Роули лишь раз отмечены как соавторы - 20 декабря 1601 г. Хенсло заплатил им 20 шиллингов аванса за «книгу» (т. е. playbook, беловую рукопись пьесы) "Indas" или "Iudas" (точное прочтение затруднительно), а через неделю авторам выдано за ту же книгу 5 
фунтов (снова очень значительная сумма). К слову, в марте 1602 г. Бёрд выплатил большую часть накопившегося долга Хенсло. Надо заметить, что в 1601-1602 гг. были заново поставлены с дополнениями многие пьесы 1590-х гг: кроме уже упомянутых, например «Испанская трагедия» Т. Кида с дополнениями Б. Джонсона (как считает ряд комментаторов, в работе принял участие и У. Шекспир - см.: Connor, 2017).

Наконец, в 1604 г. на сцену ненадолго возвращается Э. Эллин, возможно, чтобы поддержать сборы компании после переезда из Саутуорка в новый театр «Фортуна» на севере Лондона. Быть может, именно с этим связано возрождение «Трагической истории...» с дополнениями Роули и Бёрда. Первое издание текста А упоминает, что пьеса печатается так, как она была сыграна Слугами графа Ноттингема — титул, который лорд верховный адмирал Чарльз Говард (Хауард) носил с 1596 г.

Неожиданным препятствием для возрождения «Фауста» в начале 1600х гг. мог стать и закон «Об ограничении театральных злоупотреблений» (An Act to Restrain Abuses of Players, 3 Jac. 1 с. 21), принятый парламентом в 1606 г. Согласно закону, со сцены запрещалось «в насмешку или кощунственно» (“jestingly or profanely”) произносить слова «Бог», «Христос», «Троица», «Святой дух», за что полагался штраф в 10 фунтов (больше, чем весь сбор за одно представление даже очень популярной пьесы). Следы редактуры ради соответствия этому закону видны прежде всего в тексте Б: имя Бога или Христа остается только в прямых молитвенных обращениях, слово «Троица» (например, в сцене 3) почти полностью исчезает, около 10 строк текста по этой же причине не перешло из версии А в Б.

Таким образом, о сценической истории «Фауста», в отличие от истории текстуальной, известно поразительно много. Пьеса пережила как минимум два, а скорее три, возрождения с интервалом в 4-5 лет, не считая постановок на выезде, в трактирах, работавших как театры, а возможно, и силами других трупп - постановок, о которых не сохранилось никакой информации, хотя они, как это известно в отношении других пьес, скорее всего, были.

\section{РАННИЕ ИЗДАНИЯ ТЕКСТА \\ ТРАГИЧЕСКОЙ ИСТОРИИ ДОКТОРА ФАУСТА»}

Первое упоминание об издании «Трагической истории...» относится к 7 января 1601 г., когда в Реестре компании книготорговцев (Stationers' Register) появилась регистрационная запись о том, что права на выход в свет «пьесы о докторе Фаусте» (“the plaie of Doctor ffaustus”) закреплены за книготорговцем Томасом Бушеллом (Thomas Bushell, ум. после 1618, издал также 
ранние сатиры Т. Миддлтона) (A transcript ..., 1876: 178). Неизвестно, вышло ли в свет издание 1601 года. Сохранилась единственная копия издания 1604 года, которое и представляет собой наиболее ранний известный нам текст (вариант А), переизданный в 1609 г. (сохранилось три экземпляра), и в 1611 г. (один экземпляр). Печатником первого издания был Валентин Симмз (Valentine Simms, ?-1622), из типографии которого вышли ранние версии ряда шекспировских пьес — «Ричарда III», «Ричарда II», «Генриха IV» (обе части), «Много шума из ничего», знаменитое первое («плохое») кварто «Гамлета», а также маски Б. Джонсона и «Недовольный» Дж. Марстона. Издания 1609 и 1611 гг. были напечатаны Джорджем Элдом для продажи в магазине Джона Райта. Во втором и третьем издании текста А название изменено по сравнению с вариантом 1604 года - вместо «Трагической истории д<-ра> Фауста, как она была сыграна слугами его светлости графа Ноттингема» (The Tragicall History of D. Faustus as It Hath Bene Acted by the Right Honorable the Earle of Nottingham His Seruants) появляется, уже без связи с театральной компанией, «Трагическая история ужасной жизни и смерти доктора Фауста» (The Tragicall History of the Horrible Life and Death of Doctor Faustus). В издании 1609 года впервые имя автора указано полностью - Ch. Marlow но в версии 1611 года снова появляется знакомое с 1604 года “Ch. Marl.”.

При всем их различии, текст А и текст Б объединяет имя книготорговца Дж. Райта (John Wright, ?-1658). Именно в его магазине, как указано в части тиража, должно были продаваться первое кварто «Сонетов» Шекспира. Роль Райта в появлении на свет текста Б пока, к сожалению, мало изучена. Любопытны два факта: во-первых, несмотря на значительные изменения в тексте, заглавие по сравнению с изданиями 1609 и 1611 гг. в версии 1616 года осталось неизменным (кроме удаления слова «ужасной» — “horrible”). Зато изменилось имя автора — “Ch. Marklin”. Текст Б переиздавался 5 раз - в 1619, 1620, 1624, 1628 и 1631 гг. В издании 1619 года Райт меняет имя автора на “Ch. Mar.” и добавляет к названию строку «с новыми дополнениями» (“with new additions"), что сохраняется во всех дальнейших версиях, хотя никаких дополнений с 1616 года не производилось.

Так как знакомство Марло с немецкой народной книгой Шписа остается не доказанным, можно быть уверенным только в том, что драматург знал ее английский перевод П. Ф., вышедший в 1592 г. (возможно, существовало и более раннее издание). После смерти книготорговца и печатника Эдварда Уайта (Edward White), выпустившего три последующих издания этой книги о Фаусте $(1608,1610,1618)$, права на нее на каком-то этапе тоже перешли к Райту, который издавал ее дважды $(1636,1648)$, причем с той же гравюрой на 
титульном листе, что и в его изданиях «Трагической истории...». Эту гравюру сохранили и все издания трагедии Марло и анонимной книги после Реставрации, а титульный лист «Трагической истории» «в том виде, как ее играют сейчас» ("as it is now acted") 1663 года указывает местом продажи тот же самый магазин Райта «под знаком Библии около Ньюгейта», но владельцем его (Райт к тому времени уже умер) назван бывший партнер Райта Уильям Гилбертсон (William Gilbertson).

\section{ЗАКЛЮЧЕНИЕ}

Изучение ранней истории и возможной датировки «Трагической истории доктора Фауста», как мы могли видеть, оставляет мало простора для мифологизирования и много вопросов. Отдельным и наиболее серьезным из них остается вопрос о том, какой из текстов ближе к оригинальной версии Марло. Мы планируем посвятить ему отдельную обзорную статью. Но и в отношении более простых вопросов ясности мало. Если аргументов в пользу ранней датировки (1588-1589 или по крайней мере 1590) все же больше, чем в пользу поздней (1592-1593), то вопросы о возможных источниках, путях заимствования и воспроизведения сюжетных параллелей и сценических формул, возможной «моде» на сюжет о Фаусте и о культурной игре вокруг него остаются пока практически без ответа. Такой ответ, при всей его сконструированности и неполноте, может дать только общее исследование о фаустовском сюжете в европейской литературе XVI-XVII вв. Для этого прежде всего необходимо выйти из тени шпенглерианских рассуждений о «фаустовском» характере европейской культуры в целом и попытаться определить, какую роль этот сюжет и герой могли играть в догетевскую эпоху.

\section{СПИСОК ЛИТЕРАТУРЫ}

Горбунов, А. Н. (2019) Доктор Фауст: Люцифер или Прометей? // Марло, Кристофер. Трагическая история доктора Фауста / изд. подгот. А. Н. Горбунов, В. С. Макаров, Д. Н. Жаткин, А. А. Рябова. М. : Наука. 324 с. С. 163-206. (Серия: «Литературные памятники»).

Захаров, Н. В. (2018) Образ Кристофера Марло и псевдобиографический подход в современной массовой культуре // Горизонты гуманитарного знания. № 3. С. 62-71. DOI: 10.17805/ggz.2018.3.4

Колесник, В. А., Макаров, В. С. (2018) Дьявол на сцене «Белл Сэвидж»: эпизод антитеатральной полемики в Англии XVI-XVII вв. // Горизонты гуманитарного знания. 2018. № 3. C. 72-89. DOI: 10.17805/ggz.2018.3.5

Марло, К. (2019) Трагическая история доктора Фауста / изд. подгот. А. Н. Горбунов, В. С. Макаров, Д. Н. Жаткин, А. А. Рябова. М. : Наука. 324 с. (Серия: «Литературные памятники»). 
A transcript of the registers of the company of stationers of London; 15541640, AD (1876) : in 5 vols. / ed. by E. Arber. L. : Privately printed. Vol. 3. 704 p.

Connor, F. X. (2017) Additions to the Spanish Tragedy: Introduction // The New Oxford Shakespeare: The complete works : Critical reference edition : in 2 vols. / ed. by G. Taylor, J. Jowett, T. Bourus, G. Egan. Oxford ; N. Y. : Oxford University Press. Vol. 1. xcvii, 1516 p. P. 1082-1088.

Doctor Faustus: A critical guide (2010) / ed. by S. M. Deats. L. : Continuum Books. xiii, 200 p.

Henslowe, P. (1904) Henslowe’s diary : in 3 vols. / ed. by W. W. Greg. L. : Arthur Bullen. Vol. 1: Texts. li, 240 p.

Henslowe, P. (1907) Henslowe papers, being documents supplementary to Henslowe's diary / ed. by W. W. Greg. L. : Arthur Bullen. 187 p.

Kocher, P. H. (1940) The English Faust Book and the date of Marlowe's Faustus // Modern Language Notes. Vol. 55. No. 2. P. 95-101. DOI: $10.2307 / 2910133$

Kocher, P. H. (1943) The early date for Marlowe's Faustus // Modern Language Notes. Vol. 58. No. 7. P. 539-542. DOI: 10.2307/2911069

Levin, H. (1952) The overreacher: A study of Christopher Marlowe. Cambridge : Harvard University Press. xii, 204 p.

Marlowe's Doctor Faustus, 1604-1616 (1950) : Parallel texts ed. by W. W. Greg. Oxford : At the Clarendon Press. xiv, 408 p.

Pinciss, G. M. (1993) Marlowe's Cambridge years and the writing of Doctor Faustus // Studies in English Literature, 1500-1900. Vol. 33. No. 2: Elizabethan and Jacobean drama. P. 249-264. DOI: 10.2307/450998

Rowlands, S. (1872) The knave of clubs. [Glasgow] : Printed for the Hunterian Club. 48 p.

The historie of the damnable life and deserved death of Doctor John Faustus (1592) / Newly imprinted, and in convenient places imperfect matter amended: according to the true copie printed at Franckfort, and translated into English by P. F. Gent. L. : By Thomas Orwin, and are to be solde by Edward White, dwelling at the little north doore of Paules at the signe of the Gun. [2], 80, 4 p.

The judgment of God shewed upon one John (Faustus) doctor in divinity. (1695) [L.] : Printed for A.M.W.O. and Tho. Thackeray at the Angel in Duck-Lane. [Электронный ресурс] // English Broadside Ballad Archive. URL: http://ebba. english.ucsb.edu/ballad/20760/ [архивировано в WaybackMachine] (дата обращения: 10.10.2018).

Zimansky, C. A. (1962) Marlowe's Faustus: The date again // Philological Quarterly. Vol. 41. Issue 1. P. 181-187.

Дата поступления: 15.10.2018 2. 
Макаров Владимир Сергеевич - кандидат филологических наук, доцент кафедры германской филологии Православного Свято-Тихоновского гуманитарного университета. Адрес: 109651, Россия, г. Москва, ул. Иловайская, д. 9, корп. 2. Тел.: +7 (495) 646-71-38. Эл. адрес: mail@vmakarov.name

Makarov Vladimir Sergeevich, Candidate of Philology, Associate Professor, Department of Germanic Philology, St. Tikhon's Orthodox University. Postal address: Bldg. 2, 9 Ilovaiskaya St., 109651 Moscow, Russian Federation. Tel.: +7 (495) 646-71-38. E-mail: mail@vmakarov.name

Для иитирования:

Макаров В. С. «Трагическая история доктора Фауста»: вопросы датировки и издания [Электронный ресурс] // Горизонты гуманитарного знания. 2018. № 6. C. 20-34. URL: http://journals.mosgu.ru/ggz/article/view/894 (дата обращения: дд.мм.гггг). DOI: 10.17805/ggz.2018.6.2 